International Journal of Applied Linguistics \& English Literature

ISSN 2200-3592 (Print), ISSN 2200-3452 (Online)

Vol. 1 No. 5; September 2012 [Special Issue on General Linguistics]

\title{
From Polarity to Plurality in Translation Scholarship
}

\author{
Abdolla Karimzadeh \\ University of Bergamo, Italy \\ E-mail: abdollah.karimzadeh@gmail.com \\ Ebrahim Samani (Corresponding author) \\ Universiti Putra Malaysia, Malaysia \\ E-mail: ibrahim.samani@gmail.com
}

Received: 07-07- 2012

Accepted: 23-07- 2012

Published: 03-09- 2012

doi:10.7575/ijalel.v.1n.5p.76

URL: http://dx.doi.org/10.7575/ijalel.v.1n.5p.76

\begin{abstract}
Review of the literature in translation studies shows that translation scholarship can be discussed in 3 Macro-levels including 1) Corpus-based studies, 2) Protocol-based studies, and 3) Systems- based studies. Researchers in the corpus-based studies test the hypothesis about the universals of translation. They also try to identify translation norms and regular linguistic patterns. This scholarship aims at showing that the language of translation is different from that of non-translation. The other purpose is to identify the techniques and strategies adopted by the translators. In protocol -based studies, the researchers study the mental activities and the individual behaviors of the translators while translating. They aim to describe the behavior of professional translators (versus translator trainees) during the process of translation in a bid to identify how they chunk the source text (unit of translation) and to describe how the translation trainees develop their translation competence. These studies are longitudinal for the reason that they aim to investigate the change of intended behaviors in the subjects of the study. Like corpus-based studies, they are experimental and data for analysis are collected by various methods including the translators' verbal report, keystroke logging, eye tracking, and so on. Recently, in a method called "triangulation", they combine the above-mentioned methods of data collection to test their hypotheses on a stronger experimental basis. To collect the data, they also employ the methods used in neurology (for example the technology of Electroencephalogram) in order to obtain information on the physiological processes in the brains of the translators while translating. And finally in the systems-based studies, the researchers analyze more extended systems of production, distribution, and consumption of translations and their impacts on the target culture in a specific socio-cultural context. Differentiating these levels does not mean that there is a fragmentation in translation scholarship. Rather translation scholarship despite having pluralistic frameworks is focused on a single object of study. In other words, differentiating these levels is related to the method of research rather than the object of the research. This paper makes an attempt to shed light on the mentioned levels and then to introduce some new areas which have not been discussed widely. It also tries to introduce a systematic framework for historical research of translation based on Pym's theory of humanizing translation studies and finally to discuss the metaphorical concept of unity in diversity from the vantage point of translation studies.
\end{abstract}

Keywords: corpus- based studies; protocol-based studies; system-based studies; experimental studies; historical research of translation; dehumanized translation scholarship; humanized translation scholarship

\section{Introduction}

Translation studies in the history of literature and philosophy has merely been limited to criticizing translations of the literary and philosophical texts or holy scriptures (especially the Bible). In fact, the earliest approach toward translation scholarship is based on hermeneutics in which translation is a sample of major problems including interpretation and understanding of texts (Palumbo, 2009, pp.5-10). This new approach to translation scholarship which has been revived after the introduction of poststructuralisim and deconstructionism has recently focused its attention tosuch issues asintertexuality and uncontrollable linguistic polysemy and aims at finding that how translation can be loyal to source language writers despite asymmetricality of languages. 
International Journal of Applied Linguistics \& English Literature

ISSN 2200-3592 (Print), ISSN 2200-3452 (Online)

Vol. 1 No. 5; September 2012 [Special Issue on General Linguistics]

This concern was raised in the first quarter of the 19th century when Schleiermacher, a German philosopher, discussed whether writers should be loyal to readers or writers (Palumbo, 2009, pp. 5-10).

After introduction of his complete framework toward translation scholarship, James Holmes criticized all earlier translation scholarships due to being biased and designed a descriptive method in translation scholarship that according to him, studied all translation phenomena without any bias. However new theorists have been criticized as being a new form of prescriptivism (Pym, 2009).

An overview on the history of the translation leads us to the conclusion that translation scholarship has never been free from the pestilence of polarity. Once source-orientedness was a dominant discourse and now extremist target-orientednessis, whatVenuti describes as"cultural narcissism" and Pym as "extremist nationalism" (Pym, 2009).

In the source-oriented theories of translation such dichotomies as free/literal translation, overt/covert translation (House,1997), semantic/communicative translation (Newmark,1981), documentary/instrumental translation (Nord,1991), foreignizing/domestifying translation (Venuti,1995), and acceptable/adequate translation(Toury,1980) were overriding, while in the target-oriented theories of translation, such binaries have been downplayed and faithfulness(relationship between source and target text)and have been replaced by loyalty(relationship between people involved in translation)(Nord,1997,p.152),in other words, the relation between texts has been replaced by the relation between the people, the same thing that Pym(2008) calls from dehumanizing to humanizing translation history.

In the current paper, an attempt has been made to discuss the frequently-used frameworks in translation scholarship after the Second World War in the aftermath of a discursive turn in translation scholarship and the rise of a new field called "translation studies". Then a new discursive turn which has recently been proposed by Pym will be discussed and that is "Humanizing vs. Dehumanizing translation scholarship". Following on, some new research areas will be Discussed which are the first of their kinds in the field of translation Studies and which can open a new horizon for would-be researchers. The importance of the present paper lies in the fact that it sheds light on the latest developments in this area of inquiry and introduces potential research areas and common research methods in translation studies. The novel research methods introduced in this paper can contribute to orientating the would-be researchers towards more dynamic research areas in translation studies as well as deepening the theoretical knowledge of the practitioners of translation about their profession. The rationale behind the current paper is to acquaint those interested in translation studies with already existing as well as potential research methods in this field.

\section{Levels of translation scholarship}

Review of the literature in translation studies shows that translation scholarship can be discussed in 3 Macro-levels such that almost all of the research approaches can be fit in the heart of one of the three-levels. These levels include: 1) corpus-based studies (product-oriented studies in Holmes' wording), 2) protocol- based studies (process- oriented studies in Holmes' wording), 3) systems-based studies (function-oriented in Holmes' wording) (Palumbo, 2009). Following will be a detailed discussion on these three levels.

\subsection{Corpus-based scholarship}

Corpora are either a collection of written authentic texts or a transcription of recorded speech which is collected with systematic methods to be used for computational processing. These corpora are mostly used in linguistics. Earlier corpus-based scholarship dates back to 1960s. But corpus-based linguistics developed in 1980s and 1990s. During these two decades, the linguists like John Sinclair, took advantages of increasing capacity of computer memories to collect a large collection of authentic texts. Nowadays, computer-readable corpora are available in many of languages and they are used for research and lexicography (Baker, 1995).

Corpora have different types. Public corpora include different types of text and do not belong to any particular area. Specialized corpora include certain types of texts or are related to specific areas. Learner corpora contain texts produced by learners. Monitoring corpora are used to follow the language changes over time and historical corpora are related to different historical periods. All of these corpora can include texts related to several languages. Multilingual corpora can be used, in addition to the field of translation studies, in the study of language and cultural differences, and for practical purposes (mainly in pedagogy and lexicography) (Baker 1995).

In the field of Applied translation studies, corpora play a role in translator training and in the development of computer assisted translation and machine translation systems. More precisely, these corpora are a treasure of 
International Journal of Applied Linguistics \& English Literature

ISSN 2200-3592 (Print), ISSN 2200-3452 (Online)

Vol. 1 No. 5; September 2012 [Special Issue on General Linguistics]

earlier translations and thus may be a complementary to dictionaries or text archives that are written in the target language ("parallel texts" as it was called earlier). Translators use these corpora to ensure reliable applications in different conditions; when translating into the second language, in translating specialized texts that the translator does not specialize in, and when the translator is concerned about interference of source language. Corpus based translation scholarship became important in 1980s but possibility its application in translation scholarship became clear in 1980s and certain research programs were defined for this. Subsequently, researchers began to collect various types of multilingual corpora (comparable and parallel). In this decade, for the first time, corpora were used to describe translation characteristics (versus original text) (Baker, 1995).

In these corpora, researchers examine so many hypotheses known as "universals of translation" including tendency to explicitation, tendency to simplification, tendency to strange collocations, tendency to unique linguistic elements, tendency to normalization, etc. they use case studies to test their hypotheses to confirm presence or lack of universals of translation. For example, the hypothesis that tendency to explicitation is the inherent characteristic of translated text has been confirmed by using corpora. With these studies, they identify translation norms followed explicitly by the community of translators. The reason for these studies is to show that language of translation is different from that of non- translation. The other objective is to recognize regular patterns of language in a bid to determine techniques and strategies used by translators(Baker, 1996).

\subsection{Protocol-based scholarship}

Protocol- based scholarship is defined as those scholarships which examine organizational, mental, and cognitive processes of translation as a mental activity (cognitive psychology) and individual behavior of translators (behavioral psychology) in the process of translating. They aim to describe the behavior of professional translators (versus translator trainees) during the process of translating to identify how they chunk the source text (unit of translation) and to describe how the translation trainees develop their translation competence. These studies are longitudinal for the reason that they aim to investigate the change of intended behaviors in the subjects of the study (Tirkkonen-Condit \&Jaaskelainen, 1991). In these studies, experimental data are used to examine behavioral changes. The mentioned data are obtained from the following sources:

\subsubsection{Verbal report}

These reports are of three kinds: the introspective, concurrent and retrospective. In introspective reports, participants analyze themselves during the test of intellectual process. Retrospective reports are those reports prepared about the thinking process after a task has been finished. Concurrent reports are those that are being prepared while the task is in the progress. When preparing this report, subjects are notasked to bring up certain information, but they have to express everything that they are thinking about. There are different opinions about the validity of various verbal reports. However, the concurrent reports have mostly attracted the attention of translation scholars (JääsKeläinen\&Tirkkonen-Condit, 1991).

\subsubsection{Think-aloud protocol (TAP)}

Think-aloud Protocol (TAP) is another version of the verbal report. Translators are asked to report everything striking to their minds and all the acts that they do while translating. Translator's remarks are recorded as audio or video files and then are transcribed on a paper. The resulted text is called Think-aloud protocol (TAP).

For the study of such topics as problem solving strategies, (Krings, 1986;Lorscher, 1991) use of referential elements, (Livbjerg\& Mees2003) and differences between novice and professional translators (JääsKeläinen\&Tirkkonen-Condit, 1991) Researchers have used Think-aloud protocols (TAP). Recent researchers have reviewed Think-aloud protocols and other methods of verbal report because the validity of these methods, rather than be proven, has been taken for granted (Bernardini, 2001). There are doubts about the application of TAPs for professional translators, because they have automatized some skills. Therefore, they may set aside their short-term memories, thus, do not report information about their mental operations. Researchers have expressed other concerns including the potential impact of the think-aloud on the process being studied, lack of a clear definition of the subject of study in many protocol-based studies and lack of a definition of the concept of the "problem" (Tirkkonen-Condit \&Jaaskelainen, 2000). With the help of TAP and other similar methods, some aspects of the translation process are now clear. For example, it is clear that text processing is not linear, but recursive (Baker, 1995). Also, it is proven that the translator's behavior, in parallel with "regularity" and "atomization" of translation, changes and that the emotional state of translator and his/her involvement with the work of translation has an impact on his/her performance (Baker,1995).Regarding differences between professional and novice translators, it has been found that professional translators are more aware of the issues 
International Journal of Applied Linguistics \& English Literature

ISSN 2200-3592 (Print), ISSN 2200-3452 (Online)

Vol. 1 No. 5; September 2012 [Special Issue on General Linguistics]

like the function of translation and the expectations of the target addressees (Tirkkonen-Condit \&Jääskeläinen, 2000).

\subsubsection{Key stroke logging}

This method is used to examine the relationship between the process of writing and translation quality. This approach has been referred with this name because the numbers of strokes that the translator enters on the computer keyboard during translating are recorded. In order to collect such data, they make use of specialized softwares such as Translog(Jakobson, 1999). This software can record all the strokes that a translator hits on keyboard and is repeatable and provides the possibility of viewing the typing process, whether in time or at run time. The raw data for this software are the final printing of translation and a full report of the typing process. This report details the data related to the duration, number of pauses, deletes or adds corrections and re corrections of each stroke. Researchers can use the data collected to find out whether best translations are the result of a smooth process (the process with minimal editing, adding and deleting), or an uneven process (i.e., with continuous editing). Repeatability of this software enables preparation of a retrospective report of the translation process. Watching replays of the production of his/her text, s/he can evaluate his/her work. For example, s/he can explain the reason for correction of a word, sentence, or complete deletion of some structures of the target text. Key stroke logging, as one of the methods of data collection during the translation process, is much easier than verbal reports and requires less time.

\subsubsection{Eye tracking}

This method is used to identify the focus of a translator. Translational behavior of a translator is tracked with special tools; behaviors such as 1) how to search a word in the dictionary or the Internet, 2) how to segment texts and find translation unit and others. With the use of this method, researchers confirm several hypotheses about the differences between professional and beginner translators. For example, they have showed that the focus of professional translators is wider than that of novice translators, because they choose longer chunks as translation units, whereas the novice translators translate word by word and they choose short translation units. In other words, the more a translator is professional, his/her chunking and textual segments will be longer and as a result, his/her focus will be beyond the word level. (Tirkkonen-Condit \&Jääskeläinen,1993).

\subsubsection{Triangulation}

Researchers using an approach called "triangulation", combine different methods of data collection to assess hypotheses about the cognitive processes involved in translation, based on strong empirical evidence. In this approach, they combine the qualitative data obtained from verbal report and TAP with quantitative data obtained from the observation. Therefore, triangulation approach is based on different methods of collecting, elicitation, and interpretation of data. To define this method the following metaphor is used. "To determine one's position when navigating in the unknown waters, several different points should be considered" and, therefore, to discover the nature of the translation process, several tools of data collection should be used simultaneously (ALves, 2003). This is done to ensure validity of data obtained from observation. Moreover besides verbal report, other methods of data collection in triangulation approach include: eye tracking and key stroke logging.

Recently, these data are collected through using neuroscientific methods (for example, electroencephalogram technology) to collect information regarding physiological processes of nerves, which occur in translator's brain when translating (Palumbo, 2009).

James Holmes (1972) introduced this branch of research for the first time into the field of translation studies(Homes, 1988).

\subsection{Systems- based studies}

These studies date back to 1970s when a discursive turn took place in translation studies. (Snell-Honby, 2006). In that decade, translation scholarship shifted its orientation from dominant approaches in linguistics to historical and socio-cultural approaches. These approaches pay much attention to the role played by the target text, considering it a determinant factor in decision makings on translation. These studies posit that literary systems generally and translation system specifically are shaped under specific historical and socio-cultural contexts. So, translation scholarship, instead of exploring texts and text analysis, should focus on more extended systems of production, distribution and consumption of texts as cultural commodities and deal with new issues such as the role played by translations in the formation of literary systems, power struggles and status of translations as rewritings of the originals by using the tools of cultural history and cultural studies. During these years, overemphasizing on this approach has led to the dominance of issues related to culture, ideology, and ethics. This

\footnotetext{
Page | 79 
International Journal of Applied Linguistics \& English Literature

ISSN 2200-3592 (Print), ISSN 2200-3452 (Online)

Vol. 1 No. 5; September 2012 [Special Issue on General Linguistics]

shows that translation scholarship has shifted from source-orientedness to target-orientedness. The researchers in the non-literary areas also propose theories prioritizing the socio-cultural factors governing on the target culture. Some of the theories frequently recited in systems-based studies include Even Zohar's polysystem theory, Vermeer's theory, Vermeer's Skopos theory,Apia's ethnographic translation andHaroldo de Campos'scannibalist theory of translation.

\section{From dehumanizing translation studies to Humanizing translation studies}

Anthony Pym (2008) believes that in systems- based translation, social role of translators has been forgotten and now is the time to lead translation from dehumanization to humanism. According to Pym, up until recently, translation has been the object of study and translators themselves as subjects and producers of translation have never been studied. As Pierre Bourdieu as cited in Pym (2008) points out, sometimes it is necessary to focus on subjective instead of objective or vice versa, in other words, it is necessary to put ourselves (translators or researchers) as the object and focus of study. According to Pym, moral mission of translation studies is to improve relations between cultures and translation studies should consider all active people in all spheres of human interaction so one of the missions of Translation Studies should be narration of relationships between culture and international relations. He challenges Toury's systems-based translation studies on the grounds that they are dehumanized and neo-formalist and invites researchers to help move translation scholarship from static to dynamic, fromuni- polar to multi-polar orientation, and from monovocality tomultivocality (Pym, 2008). In this section of the paper, attempt will be made to introduce steps taken to move from dehumanized translation scholarship.

\subsection{Humanizing translation scholarship}

Based on humanism theory, Pym (2008) offers a systematic theoretical framework for research on translation. He believes that Historiography of translation has solely been limited to listing the names of translators and translations and sometimes to historical and geographical references. So, he accuses it of being impressionistic with no scientific basis and framework. In his pathology of scholarship on translation history, Pym has identified at least 7 pestilences including 1) Piling a list of archaeological data, 2) Not relying on historical documented evidences, 3) haphazard periodizations, 4) overemphasizing on the target culture, 5) seeing translation merely as an impassive thing, not a potential force to change the history, 6) not accepting the interculturality of the translators, 7) using unfalsifiable hypotheses. (Pym, 1992)

Taking these pestilences into account, he introduces two general principles to the researches on the history of translation: Principle one: Move from texts to translators, Principle two: concentrate on the interculturality of the translators. According to the first principle, research should be focused on translations rather than translators. Benefits are that several works can be done simultaneously: a) Discovery of obscure translators, b) Analysis of multi- discursiveness of translators, c) Analyzing the discursive turns of the translators, d) Analyzing the social networks of translators. In order to shed light on Pym's principles on history of translation scholarship, the above mentioned issues will be explained briefly with examples from Iranian history:

\subsubsection{Discovery of obscure translators}

In Iran's cultural history, there are translators who have become famous not for being translator but for being a politician, political activist, writer, philosopher, etc. According to Pym (2008), a number of archives need to be prepared for their biography. Then not only history but also implicitly the reasons for the marginalization of many translators as important cultural figures will be revealed. For example, compiling biographies of people such as "Haidar Khan the Translator", "IrajEskandari", "Ahmad Mahmoud", "EbrahimYounesi", "Behazin", "Abdul HosseinNushin", "Ahmad Mahmoud", and dozens of translators and writers whom there have not been any mention of in literature can help to humanizing translation scholarship in Iran's translation history. These people all were political activists and have spent their lives fighting politically, in prison and in exile. But were not they translators? This is what Pym states. Pym notes that humanizing scholarship must pay attention to the cultural and ideological positions of translators, their political party affiliation, and totheir record of political and cultural activities, then they can be directed to text research (first principle), because in his opinion, translators as cultural agentsare not passive objects, but have the potentiality to change the history (Pym 2008). Behazin is popularly known as the father of translation in Iran and has translated great works like "King Lear", "Hamlet," "Macbeth" by Shakespeare, "Faust" by Goethe, , but was affiliated to the communist Party, with Marxist tendencies, was one of the founders of the Iranian Writers Association, was a political activist and had spent 
International Journal of Applied Linguistics \& English Literature

ISSN 2200-3592 (Print), ISSN 2200-3452 (Online)

Vol. 1 No. 5; September 2012 [Special Issue on General Linguistics]

years in exile and in prison ${ }^{1}$. Or Haidar Khan the Translator was one of the activists in the Constitutional Movement of Iran who had fled to Iran because of the Caucasus Muslims torture by tsarist Russia agents. He had a good mastery on Farsi, Turkish, Georgian, Armenian and Russian, and had translated "the Gospel of Barnabas" into Farsi, he was also a fellow combatant to SattarKhan(the leading figure of the Constitutional Revolution), and he was present in all the constitutional combats. He was involved as an engineer in Shah Abdul Azim railway construction project. He had masterminded the assassination of Mohammad Ali Shah (the king of Iran), and SeyyedAbdollahBehbahani(leading cleric of the Constitutional revolution)was murderedby his followers (Bamdadi, 1984).

\subsubsection{Analyzing the multi-discursiveness of the translators}

Pym (2008) in his history of translation scholarship theory states that translators simply do not translate, but show interest in other discourses alongside the translation discourse and each of these discourses have to be discussed by translation scholars. Here, we cite "EbrahimYounesi" as an example who translated 80 novels from English to Persian. But translation is only one of the discourses in his life. He was the first governor of Kurdistan in Iran after the Islamic Revolution. He was of the surviving officers of the Communist Party who after the coup was sentenced to death, but because he had lost his leg in army, was commuted to life imprisonment. "Big dreams" of Charles Dickens, "the storm" of Shakespeare, "a pair of blue eyes" of Thomas Hardy, are among his translations("Bibliography of Ebrahim Yunesi," 2011,June 2).

\subsubsection{Analyzing the discursive turns of the translators}

Pym (2008) states that scholars on the history of translation should examine cause and effect and analyze why a certain translator constantly shifts from one discourse to other discourses, what relationship exists between these discourses? For example, "Abdul HosseinNushin", who is popularly known as "father of modern Iranian theater", has translated and directed many of the world's leading plays. In Moscow, he compiled a glossary for research on Shahnameh. He has written many works and launched theater halls ofFerdowsi and Farhang. But his theaters were soon closed. Why? Because, he was also one of the founders of the Communist Party and the closure of theaters was because of the mission that the Party had given to him (Agheli, 2001).

\subsubsection{Analyzing social networks of the translators}

Translators do not work in vacuum and isolation. Translation is an industry in which a large network of production, distribution, and consumption are working and interacting. These networks have a relationship with individual translators. From book publishers to book sellers, the government entities that issue the license, book buyers, sponsors and patronage, book fairs and festivals awarding the best written works and translation and so on. Pym believes that scholarship on history of translation should examine the relationships of the translators to these networks. Why certain translators choose one publisher out of dozens of publishers to work with? What is that publisher's ideological position? Why a specific translator won an award in certain award-winning book festival? What was the cause of eliminating other translators? And these whys should be ever present for scholars of translation history. Pym also points out that the scholars on translation history should record all events associated with translation on each moment and update archives because these archives will be historical documents for our future generation. (Pym 2008).

\subsection{New research in Humanizing translation scholarship}

As mentioned, in humanizing translation studies, object of study has changed and now translation scholars are looking for new objects. In the current paper due to space restrictions, there is no possibility of introducing all projects, so only few projects will be briefly introduced.

\section{Sample 1}

Wilder (2004) in her research on "Subtitle" which is one kind of multi-media translation investigated a hundred of cinema customers who loved subtitled movies. She wanted to examine what type of people and with what incentives usually go to watch subtitled movies and what the satisfaction level of people from subtitles is. The researcher asked people who had just bought tickets to watch the newly released movies with subtitles in two Summer Film Festivals in Vienna, and collect her data using surveys and questionnaires. The value of this research is that it is first of its kind on translation studies that is about "audience studies". This is a new experience in humanizing translation which examines humans instead of texts. Its findings can be added to other research areas including marketing, media and advertising, public opinion and demography and this will help to

${ }^{1}$ http://www.bbc.co.uk/persian/arts/2010/01/100110_u04_brothers_memoirs.sml

Page | $81 \quad$ This paper is licensed under a Creative Commons Attribution 3.0 License.


International Journal of Applied Linguistics \& English Literature

ISSN 2200-3592 (Print), ISSN 2200-3452 (Online)

Vol. 1 No. 5; September 2012 [Special Issue on General Linguistics]

promote research studies to the level of interdisciplinary and will expand Translation Studies. Even geographical limits of these studies can be expanded and examined more in local, regional, and international levels and their results can be compared. Due to being costly and time consuming, this type of research needs to have teams from different disciplines that can consequently help to promote translation studies.

\section{Sample 2}

In our studies, financial factors have been overlooked, so Marxist theories can be highlighted (Marxists say that the economy is crucial) (Pym, 2008). It seems that Iran's translation policy is positive towards the translation of native works into other languages (ICTS, 2005). Iranian officials consider it as a way to spread culture beyond its borders. A wide range of patriots through the translations can maintain their contact with their homeland. Academic circles consider translation as a window to new literary discourses (Payandeh, 2009). Publishers consider translations as a tool for tabbing the market, that is, the various stakeholders somehow have a benefit and a symbiosis relationship establishes between them and the economic benefits become much more highlighted: Publishers seeking to capture new markets, the government seeking to raise funds from Iranian patriots abroad, and academics seeking new employment opportunities. With this arrangement, range of social groups can be made wider and we can get one step closer to humanizing translation scholarship. Even an economic cause and effect relationship can be explained between various groups of interest; who will win more or who will win less? Why? Regarding economy and translation, Wolf (2006) a German researcher studied "the relationship between cultural capital and economic capital of the translators and publishers" and her question was why female translators' fees are lower? In the end, it was found that for women, cultural capital is more important than economic capital.

\section{Sample 3}

Pollabauer (2006), an Austrian researcher, selected asylum-seekers in the court hearing as the object of his study. He has examined oral translation from perspective of power relationship. It was found that the oral translators cooperated more with officers in charge of interview rather than political refugees. In other words, oral translators were associates to officers and power relations bring about unilateral faithfulness of translators to officers. These samples were a handful of studies that show how translation scholarship can be led from text study to human study and can expand the limit of translation scholarship and save translation studies from the deadlock in terms of the object of study.

\section{Conclusion}

The findings of this research lead us to the conclusion that during the history, translation scholarship has undergone multiple discursive turns. These turns have brought about new layering. This layering does not denote existing of fragmentation in translation scholarship. Rather, despite having multiple approaches, translation scholarship is focused on a single object of study. In other words, the issue of translation is the focal point of all these approaches. One can say that the differentiation of the mentioned levels is relating to the method of research rather than the object of research. Here the metaphor of "unity in diversity" strikes to the mind. This is the very concept of pluralism in translation studies. Pluralism not only does not signify fragmentation in translation studies, but suggests its dynamism and flexibility and can immunize this field against pestilences of polarities and contribute to the widening of translation-related studies. This paper was an attempt to provide an outline of the research methodologies in translatology. Relying on these methodologies; the would-be researchers can single a framework out for their studies. Obviously as for humanizing approach to translation scholarship, further studies are required to find new areas of inquiry. It is suggested that the would-be researchers repeat the same approach in different socio-cultural contexts to produce a sizeable body of knowledge about translation studies.

\section{References}

Agheli, B. (2001). Political and military figures in contemporary Iranina history ( ed.): Goftar Publications.

Alves, F. (Ed.). (2003). Triangulating Translation. Perspectives in Process Oriented Research. Amsterdam/Philadelphia: Benjamins.

Baker, M. (1995). Corpora in Translation Studies: An overview and some suggestions for future research. Target, $7(2), 223-243$.

Baker, M. (1996). Corpus-based Translation Studies: The challenges that lie ahead. In H. Somers (Ed.), 
International Journal of Applied Linguistics \& English Literature

ISSN 2200-3592 (Print), ISSN 2200-3452 (Online)

Vol. 1 No. 5; September 2012 [Special Issue on General Linguistics]

Terminology, LSP and Translation Studies in Language Engineering in Honour of Juan C.Sager (pp. 175-186). Amsterdam/Philadelphia: Benjamins.

Bamdadi, M. (1984). The history of Iranian men (Vol. First): Zavvar Publications.

Bernardini, S. (2001). Think-Aloud Protocols in Translation Research: Achievements, limits, future prospects.

Target, 13(2), 241-263.

Bibliography of Ebrahim Yunesi (2011,June 2). Hamshahri, p. 19,

Homes, J. S. (1988). Translated Papers on Literary Translation and Translation Studies. Amsterdam: Rodopi.

Hous, J. (1977). Translation Quality Assessment: A Model Revisited. Tübingen: Narr.

ICTS (2005). Official Website of the Iranian Center for Translation Studies.

Jaaskelainen, R., \& Tirkkonen-Condit, S. (1991). Automatized Processes in Professional Vs. Non-Professional Translation: A think-aloud protocol study In S. Tirkkonen-Condit (Ed.), Empirical Research in Translation and Intercultural Studies (pp. 89-109). Tubingen: Narr.

Jakobsen, A. L. (1999). Logging target text production with Translog. In G. Hansen (Ed.), Probing the process in translation:Methods and Results. Copenhagen Studies in Language 24 (pp. 9-20). Copenhagen:

Samfundslitterature.

Krings, H. P. (1986). Was in den KÖpfen von Übersetzernvorgeht. EineEmpirischeUntersuchung der Struktur des ÜbersetzungsprozesscsanfortgeschrittenenFranzÖsischlernern. Tübingen: Narr.

Livbjerg, I., \& Mees, I. M. (2003). 'Patterns of dictionary use in non-domain-specific translation'. In F. Alves (Ed.), Triangulating Translation. Perspectives in Process Oriented Research. (pp. 123-136).

Amsterdam/Philadelphia: Benjamins.

LÖrscher, W. (1991). Translation Performance, Translation Process and Translation Strategies. A

Psycholinguistic Investigation. Tübingen: Narr.

Newmark, P. (1981). Approaches to Translation

Oxford: Pergamon.

Nord, C. (1991). Text Analysis in Translation: Theory, Methodology, and Didactic Application of a Model of Translation-oriented Text Analysis Amsterdam: Rodopi.

Nord, C. (1997). Translating as a Purposeful Activity: Functionalist Approaches Explained Manchester: St Jerome.

Palumbo, J. (2009). Key Terms in Translation Studies. New York and London: Continuum.

Payandeh, H. (2009). "An Interview with Dr. Hossein Payandeh". In M. Akbari (Ed.), Ketabe-Mahe-Adabiyat (pp. 10-11).

Pollabauer, S. (2006). "Translation culture in interpreted asylum hearings". In Pym, Anthony, Miriam, Shlesinger \& Z. Jettmarova (Eds.), Sociocultural Aspects of Translating and Interpreting (pp. 151-162).

Pym, A. (1992). Shortcomings in the History of Translation. Babel, 38(4), 221-235.

Pym, A. (2008). Humanizing Translation History. Hermes, 42, 23-48.

Snell-Honby, M. (2006). The turns of Translation Studies. Amsterdam/Philadelphia: Benjamins.

Tirkkonen-Condit, S., \& Jaaskelainen, R. (Eds.). (2000). Tapping and Mapping the Processes of Translating and Interpreting:Outlooks on Empirical Research Amsterdam/Philadelphia: Benjamins.

Toury, G. (1980). In Search of a Theory of Translation. Tel Aviv: The Porter Institute for Poetics and Semiotics, Tel Aviv University.

Venuti, L. ([1995] 2008). The Translator's Invisibility: A History of Translation. London/New York: Routledge.

Wilder, B. (2004). A Survey among Audiences of Subtitled Films in Viennese Cinemas. Meta, 49(1), 98-101. 